\title{
A Prospective Study to study the Efficacy and Side Effects of Ormeloxifene in Regression of Mastalgia and Fibroadenoma: Is It the Ideal Drug?
}

\author{
Nidhi Gupta
}

\begin{abstract}
Ormeloxifene (Centchroman) is a novel nonsteroidal, selective estrogen receptor modulator birth control pill which has also been used recently for the treatment of mastalgia and fibroadenoma. Fibroadenomas are the most common benign breast tumors in women but worrisome for women fearing cancer. Mastalgia whether cyclic or noncyclic may be severely incapacitating for women.

This study aims to analyze the effect of this new drug on the regression of mastalgia and fibroadenoma as an alternative to presently available steroid-based drugs with significant side effects.
\end{abstract}

Materials and methods: This was a prospective study involving 100 women of reproductive age group (up to 35 years of age) attending the outpatient department (OPD) in Malhotra Nursing Home, Agra and Rainbow Hospital Pvt Ltd., Agra, India, from August 2011 to August 2014, complaining of mastalgia and/ or fibroadenoma and fulfilling the inclusion criteria.

After informed consent, these women were divided into a mastalgia group who had mastalgia with or without nodularity and a fibroadenoma group having sizes 1.5 to $2 \mathrm{~cm}$, single or multiple in one or both breasts. Ormeloxifene $30 \mathrm{mg}$ on alternate days was administered for 3 months in both the groups. Patients were followed at 1, 2, 4, 8, 12 and 24 weeks to assess response to therapy. Clinical examination, change in nodularity by palpation, breast lump size by ultrasonography, change in visual analog score (VAS) and breast tenderness were monitored. Results were analyzed using ' $t$ ' test.

Results: A total of 100 patients were included in this study. Eighty percent women belonged to the age group 25 to 35 years with a mean age of $28,31.2$ and 27.2 years in groups IA, IB and group B respectively. Mean interval between drug therapy and onset of response was $6 \pm 2$ days in mastalgia group and $15 \pm 2$ days in fibroadenoma group. 97.6 to $100 \%$ of women in the mastalgia group reported complete relief at 12 weeks of therapy with a decrease in VAS score from 10 to 3 in the first week of therapy itself while $28 \%$ of fibroadenoma group reported complete relief at 12 weeks of therapy, partial relief in $31 \%$ and equivocal response in $41 \%$. Side effects observed were allergic rash development $(2 \%)$ and a delay in menstruation of 7 to 10 days (14\%) during therapy.

\section{Associate Professor}

Department of Obstetrics and Gynecology, SN Medical College Agra, Uttar Pradesh, India

Corresponding Author: Nidhi Gupta, Associate Professor Department of Obstetrics and Gynecology, SN Medical College Agra, Uttar Pradesh, India, Phone: 09837030609, e-mail: drnidhi_gupta@rediffmail.com
Conclusion: Ormeloxifene is a novel nonsteroidal drug found to be effective in treatment of mastalgia and partially in treatment of fibroadenoma in a short period of 3 months. As compared to the drugs presently in use namely danazol and bromocriptine, ormeloxifene is safer as suggested by its side-effect profile and is cost-effective too. There is need for prospective large randomized studies to compare this low-cost drug with the standard but costly drugs being prescribed at present.

Keywords: Cyclical pain, Fibroadenoma, Mastalgia, Noncyclical pain, Ormeloxifene.

How to cite this article: Gupta N. A Prospective Study to Study the Efficacy and Side Effects of Ormeloxifene in Regression of Mastalgia and Fibroadenoma: Is it the Ideal Drug? J South Asian Feder Obst Gynae 2016;8(1):48-56.

Source of support: Nil

Conflict of interest: None

Date of received: 9 December 2015

Date of acceptance: 12 February 2016

Date of publication: March 2016

\section{INTRODUCTION}

Benign breast disease has been an enigma for treating surgeons since long. It usually affects the young population who is unsuited and unwilling for trying out radical measures but while prescribing conservative treatment, suffer from the hidden psychological fear of malignancy.

Mastalgia whether cyclic (associated with menstrual periods) or noncyclic may be severely incapacitating for the woman. Cyclical mastalgia is a common problem that can be sufficiently severe to interfere with usual activities, and has been associated with elevated mammography usage in women. Many women with mastalgia worry more about the consequences of cancer than about the pain itself.

Fibroadenomas are the most common benign breast tumors in women worrisome for women fearing cancer. Fibroadenoma is a common cause of discrete, firm and mobile lump in the breast. It is considered as an 'aberration in development and involution of ductolobular tissue' in the breast and not a true neoplasm. Fibroadenoma begins as hyperplasia of lobules from 'terminal ductal lobular units' which progressively increases in size from one to three. Most of them remain static, but 
some increase in size to more than $5 \mathrm{~cm}$ when they are named as 'giant fibroadenoma'. Multiple fibroadenomas can occur in the same breast or bilaterally. Nearly 10 to $15 \%$ of lesions regress spontaneously over the period of 6 to 60 months.

Simple fibroadenoma is usually managed by natural observation as they are benign and asymptomatic without any risk of future cancer. Complex fibroadenoma is associated with moderate risk of cancer and those associated with atypia (relative risk of $>2$ ) or family history of breast cancer should be excised. Some patients prefer to have the lump excised because of pain, discomfort, psychological reasons or fear of cancer.

Several treatment options have been explored in the past including reassurance, supportive therapy, analgesics, evening primrose oil, ${ }^{1}$ oral contraceptive pills, tamoxifen and bromocriptine with variable success rates.

Hormonal manipulation has been attempted to suppress the growth of fibroadenoma with antiestrogenic drug tamoxifen as fibroadenoma is considered to arise from hyperresponsiveness of lobular tissue to estrogen. Presence of estrogen receptors on tissues obtained from fibroadenoma has been described. ${ }^{2,3}$

Hence, we used an antiestrogen, ormeloxifene, in order to suppress the proliferation of ductolobular tissue of fibroadenoma. Ormeloxifene is a novel third generation nonsteroidal, selective estrogen receptor modulator birth control pill originally developed in India which has been in use as a weekly oral contraceptive for the past 20 years.

It has weak agonist (on endometrium and bones) and strong antagonist (on breast ductolobular epithelium) action, and, hence, which has also been put to recent use for the treatment of mastalgia and fibroadenoma.

This study aims to analyze the effect of this new drug on the regression of mastalgia and fibroadenoma as an alternative to presently available steroid-based drugs with significant side effects.

\section{MATERIALS AND METHODS}

This was a prospective study involving 100 women of reproductive age group (up to 35 years of age) with mastalgia and/or fibroadenoma, diagnosed on triple assessment (clinical evaluation, ultrasound scan and a large core needle biopsy under local anaesthesia) attending outpatient department in Malhotra Nursing Home, and Rainbow Hospital, from August 2011 to 2014 at Agra, India.

\section{Inclusion Criteria}

- History of mastalgia with or without nodularity

- Fibroadenoma $<5 \mathrm{~cm}$ size

- Age up to 35 years

\section{Exclusion Criteria}

- Giant fibroadenoma (equal to or larger than $5 \mathrm{~cm}$ )

- Polycystic ovarian disease

- Cervical hyperplasia

- Liver disease

- Pregnancy

- Lactation period for first 6 months

- Patients wishing to conceive in near future

- Patients on other oral contraceptive pills

- History of breast carcinoma or family history of breast carcinoma.

After informed consent, women were divided into a mastalgia group who had mastalgia with or without nodularity and a fibroadenoma group having sizes 1.5 to $2 \mathrm{~cm}$, single or multiple in one or both breasts.

- Group IA: Mastalgia with nodularity

- Group IB: Mastalgia without nodularity

- Group II: Fibroadenoma

A baseline breast ultrasound scan was performed, sonographic morphology of the fibroadenoma was assessed and dimensions were recorded. The medical history and examination were recorded in a predesigned proforma.

All patients were given a simple daily breast pain self-recording chart and those with severe cyclical breast pain that continued for more than 10 days in a month were included in the study. Pain score was recorded on a visual analog scale (VAS) from 0 to 10.

An ultrasound of pelvic organs was done to note any associated hyperestrogenic condition if any was also noted-polycystic ovarian disorder (PCOD), endometrial hyperplasia, ovarian cysts and fibroids.

Ormeloxifene $30 \mathrm{mg}$ on alternate days was administered for 3 months in both the groups.

Patients were evaluated after 1 week to check the tolerance to the drug and later followed at weeks 4, 8, 12 and 24 to assess response to therapy. The ease of administration of ormeloxifene facilitated compliance and acceptability.

Follow-up was also done after 6 months of stopping the therapy to look for reappearance of symptoms.

Clinical examination, change in nodularity by palpation, serial volume measurements of breast lump size by ultrasonography, change in VAS and breast tenderness were monitored. The ultrasound examination of the breast served as an objective measurement of volume assessment.

Primary objective of interest in the mastalgia group was relief of breast pain as evident on VAS of 0-10. Secondarily change in nodularity of breast as evident on palpation was recorded as complete or partial regression at follow-up visits, and relief of breast tenderness was 
assessed by palpation as presence or absence and documented on follow-up visits.

Results were analyzed using ' $t$ '-test for normally distributed data.

\section{Observations}

The study was conducted between August 2010 and 2014 in the Outpatient Department (OPD) of Malhotra Nursing Home and Rainbow Hospital Pvt Ltd. All the women coming with history of mastalgia with or without nodularity and fibroadenoma up to 35 years of age were enrolled.

One hundred and thirty-six women were screened and 36 were excluded as they did not fulfill the inclusion criteria. One hundred women were enrolled but four women were lost to follow-up on the first visit and a total of 96 women were analyzed and grouped according to their examination findings. Patients presenting with breast pain were $67(70 \%)$ with nodularity 15 $(22 \%)$ without nodularity $52(78 \%), 29(30 \%)$ women had palpable fibroadenoma of $<5 \mathrm{~cm}$. Breast pain was unilateral in $37(55 \%)$ and bilateral in $30(45 \%)$. Cyclical pain was observed in $17(25 \%)$ women and noncyclical breast pain in 50 (75\%) (Flow Chart 1).

This study was conducted on a total of 100 women whose age ranged from 17 to 35 years with a mean age of $28,31.2$ and 27.2 in group IA, IB and group B respectively. The mean parity in all the groups was 2 nd para and they belonged to an average socioeconomic status. None of the women complained of similar complaints in the past. Four women $(6 \%)$ in group IA one $(6 \%)$ in IB and two

Flow Chart 1: Disposition tree showing the number of women screened, enrolled, analyzed and lost to follow-up in the study of ormeloxifene in mastalgia and fibroadenoma group

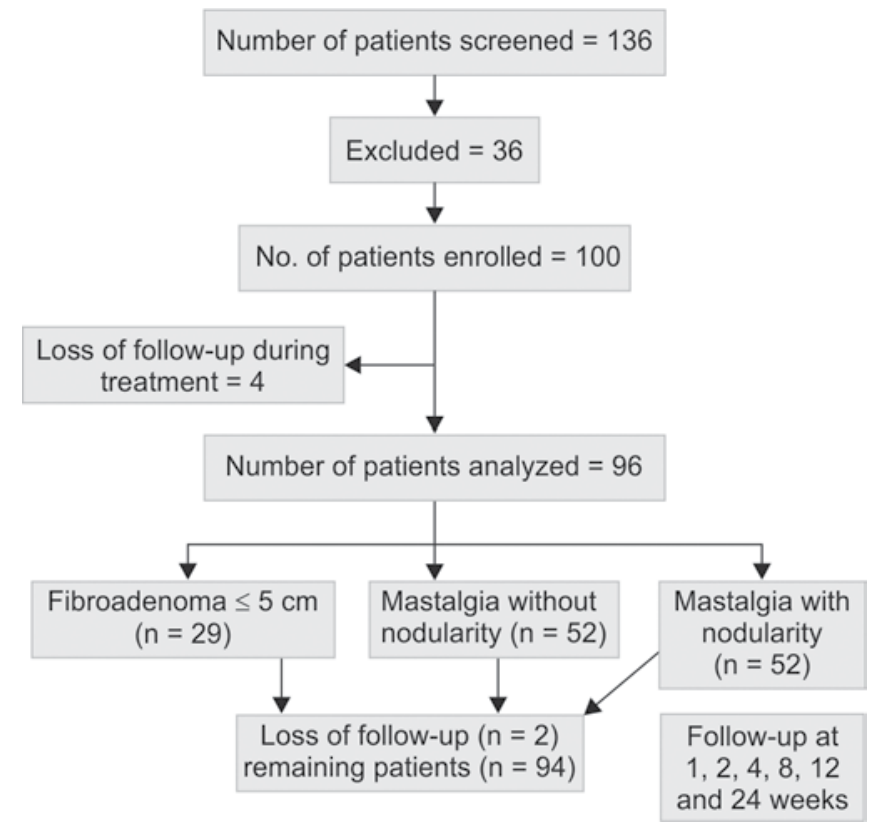

women $(4 \%)$ in group IIB gave a positive family history of similar complaints. Polycystic ovarian disorder was observed in five $(10 \%)$, one $(4 \%)$ and two $(6 \%)$ of women in groups IA, IB and II respectively. Endometrial hyperplasia (endometrial thickness $>10 \mathrm{~mm}$ ) was observed in $2 \%$ of women in group IB and II each. Ovarian cysts were observed in 2 and $1 \%$ each in group IA and II respectively. Four percent of women had fibroids on ultrasonography each in groups IA and II (Table 1).

\section{Group I (Mastalgia Group) Presence of Mastalgia}

Mastalgia was present in 67 women. Fifty-two women $(78 \%)$ had only mastalgia and 15 women $(22 \%)$ had mastalgia with nodularity.

There were two lactating women in the group whose breast pain was of more than 6 months duration. Among the married women 24 used no contraceptives, 17 had undergone tubal ligation, 20 had an intrauterine contraceptive device (IUCD) in situ and six used barrier contraception. None of them were using any sort of oral contraceptive pill.

In 12 patients $(18 \%)$, the VAS score was recorded between seven and 10 with significant disability that affected the woman's ability to work. At the end of the first week, only 70 to $90 \%$ women showed complete response and 52 to $63 \%$ women showed partial response in group IA and IB respectively. At 2 weeks, 33 to $42 \%$ women showed complete response and partial response was seen on 66 to $57.8 \%$. At the end of 12 weeks, $97.6 \%$ in the group IA and $100 \%$ women in group IB showed complete response (Table 2).

During the follow-up visits, two women returned with pain but with a lower VAS score of two and four only. They were put on medication again once a week for 3 months and responded well (Graph 1).

Table 1: Patients' characteristics in different groups

\begin{tabular}{llll}
\hline & $\begin{array}{l}\text { Mastalgia } \\
\text { without } \\
\text { nodularity }\end{array}$ & $\begin{array}{l}\text { Mastalgia } \\
\text { with } \\
\text { nodularity }\end{array}$ & Fibroadenoma \\
\hline Mean age & 28 & 31.2 & 27.2 \\
Mean parity & 2 & 2 & 2 \\
Mean BMI & 29.2 & 28.2 & 30.2 \\
S/E status & Average & Average & Average \\
Previous history & No & No & No \\
Positive family history & $8 \%$ & $6 \%$ & $4 \%$ \\
Associated & & & \\
hyperestrogenic & & & \\
conditions & & & \\
PCOD & $10 \%$ & $4 \%$ & $6 \%$ \\
Endometrial hyperplasia & - & $2 \%$ & $2 \%$ \\
Ovarian cysts & $2 \%$ & - & $1 \%$ \\
Fibroids & $4 \%$ & - & $4 \%$ \\
\hline
\end{tabular}


A Prospective Study to study the Efficacy and Side Effects of Ormeloxifene in Regression of Mastalgia and Fibroadenoma

Table 2: Comparative evaluation of effect of ormeloxifene therapy on mastalgia and fibroadenoma

\begin{tabular}{|c|c|c|c|c|c|c|}
\hline & \multicolumn{2}{|c|}{ At 1st week } & \multicolumn{2}{|c|}{ At 2 weeks } & \multicolumn{2}{|c|}{ At 12 weeks } \\
\hline & $\begin{array}{l}\text { Complete } \\
\text { response }\end{array}$ & $\begin{array}{l}\text { Partial } \\
\text { response }\end{array}$ & $\begin{array}{l}\text { Complete } \\
\text { response }\end{array}$ & $\begin{array}{l}\text { Partial } \\
\text { response }\end{array}$ & $\begin{array}{l}\text { Complete } \\
\text { response }\end{array}$ & $\begin{array}{l}\text { Partial } \\
\text { response }\end{array}$ \\
\hline Mastalgia with nodularity & $7 \%$ & $52 \%$ & $33 \%$ & $66 \%$ & $97.6 \%$ & $0.4 \%$ \\
\hline Mastalgia without nodularity & $9 \%$ & $63 \%$ & $42 \%$ & $57.8 \%$ & $100 \%$ & - \\
\hline Fibroadenoma & - & - & $3 \%$ & $21 \%$ & $28 \%$ & $31 \%$ \\
\hline
\end{tabular}

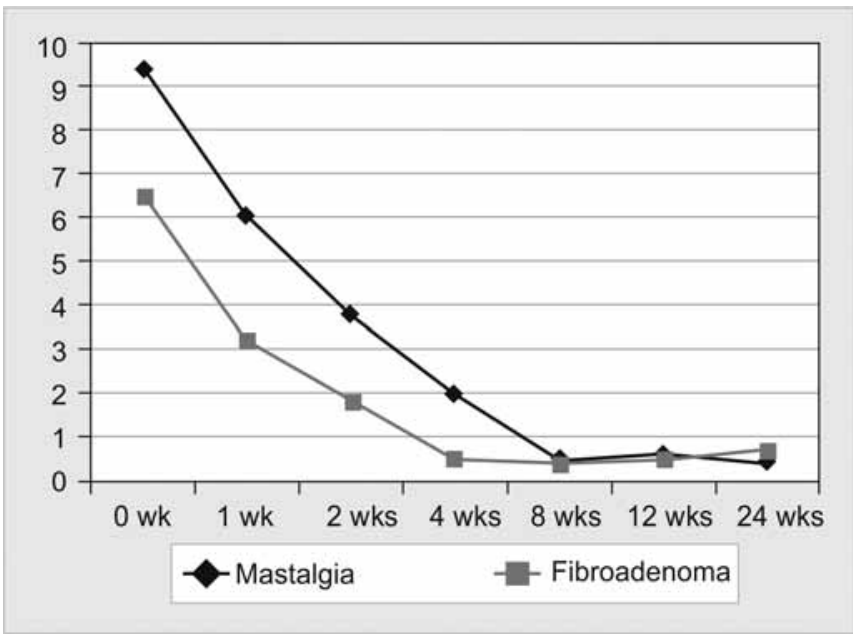

Graph 1: Response of pain to ormeloxifene according to visual analog scale scoring (Y-axis) in both the groups

\section{Nodularity and Tenderness}

Nodularity was present in 15 women with mastalgia and tenderness. At the end of 1 st week, the nodularity disappeared in two women (13\%) regressed partially in six (40\%). At the end on 12 weeks, there was $100 \%$ regression in all women. At 6 months of follow-up, only one woman complained of nodularity with mild heaviness in the breast. She was put on a once a week dose for 3 months with complete regression and good response.

\section{Group II (Fibroadenoma Group)}

Fibroadenomas were present in 29 women of which 15 (51\%) had a painless lumps and $14(49 \%)$ were painful. Breast lumps varied from 0.5 to $5 \mathrm{~cm}$, were located in one or both the breasts. Five (17\%) women had multiple lumps. At the end of 2 weeks, fibroadenoma completely disappeared in one woman, was reduced in six $(21 \%)$ and showed no change in 22 others $(76 \%)$. At the end of 12 weeks, fibroadenoma had completely disappeared in eight cases (28\%) and reduced in nine cases (31\%). There was no change in size of fibroadenoma in 12 cases (41\%). During follow-up of 6 months, none of the fibroadenomas that disappeared recurred (Graph 2).

The study has shown promising results with the drug having only a few side effects. Fifty-eight percent of the cases complained of no side effects. Fourteen percent complained of a delay in their menstrual cycle and

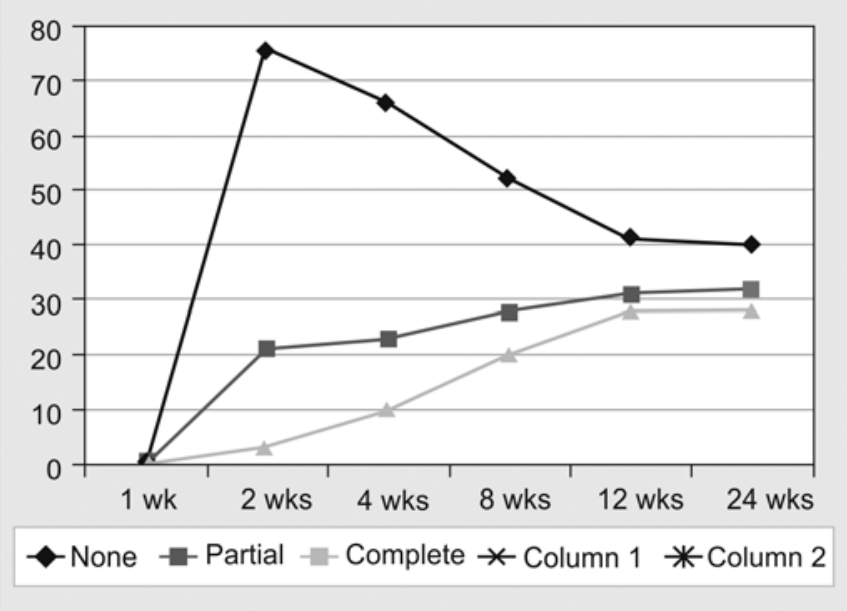

Graph 2: Response of fibroadenoma to ormeloxifene as seen on ultrasound before and after the treatment (weeks on X-axis and percentage of women showing response on Y-axis)

$8 \%$ cases had amenorrhea. The above two side effects reverted back to normal within 2 to 3 months of stopping treatment.

Eighty percent of cases complaint of gastric upset, $6 \%$ vague abdominal pain and $4 \%$ had headache. Drugrelated rash developed in two patients which was temporary (Table 3).

\section{RESULTS}

Eighty percent women belonged to the age group 25 to 35 years with a mean age of 27.4 years, mean parity 2nd and mean BMI 32.1.

Seventy percent patients had mastalgia with or without nodularity and 30\% had fibroadenoma ranging from 1.5 to $5 \mathrm{~cm}$ in size.

Further on patients with breast pain only (78\%) far outnumbered those with mastalgia and nodularity both $(22 \%)$.

Table 3: Detailed side effects seen in cases treated with ormeloxifene

\begin{tabular}{llll}
\hline Sl. no. & Side effect & No. of patients & Age (\%) \\
\hline 1 & No side effect & 58 & 58 \\
2 & Delayed cycle & 14 & 14 \\
3 & Temporary amenorrhea & 8 & 8 \\
4 & Gastric upset & 8 & 8 \\
5 & Vague abdominal pain & 6 & 6 \\
6 & Headache & 4 & 4 \\
7 & Drug-related rash & 2 & 2 \\
\hline
\end{tabular}


Noncyclical pain was recorded in $75 \%$ and cyclical pain was recorded in $25 \%$ subjects, with a VAS scoring of 10 in $80 \%$ and VAS scoring of seven to 10 in $20 \%$ subjects.

Mean interval between drug therapy and onset of response was $6 \pm 2$ days in mastalgia group and $15 \pm$ 2 days in fibroadenoma group.

Breast pain was unilateral in $55 \%$ patients and bilateral in $30 \% .97 .6$ to $100 \%$ of women in mastalgia group reported complete relief at 12 weeks of therapy while $28 \%$ of fibro-adenoma group reported complete relief at 12 weeks of therapy, partial relief in $31 \%$ and equivocal response in $41 \%$.

During follow-up after the end of study period, 3\% patients returned with the complaint of pain with a VAS scoring of 2 to 5 (mild pain). These were again put on drug therapy at decreased frequency of drug administration (once a week for 3 months) with a good response.

None of the patients with fibroadenoma with regression during the study period returned with relapse during follow-up.

Side effects observed were rare, namely allergic rash development (2\%) and a delay in menstruation of 7 to 10 days $(14 \%)$ during therapy.

\section{CONCLUSION}

Centchroman is a novel nonsteroidal drug found to be effective in ameliorating the symptoms of mastalgia and partially in reduction of size of fibroadenoma in a short study period of 3 months. The drug is inexpensive and is well tolerated with scanty periods or delayed menses as the only side effect. It has virtually none of the side effects associated with oral contraceptives, no effect on hypothalamic-pituitary axis and has a large margin of safety. Centchroman scores over currently used drug therapies namely tamoxifen, in being a nonsteroidal molecule, hence, devoid of steroidal side effects in long-term therapy. The ease of administration of the drug facilitates patient compliance and acceptability and the marked relief of symptoms results in higher clientele satisfaction, proving itself a pride molecule for India. There is need for prospective randomized studies to compare this low cost drug with the standard but costly drugs being prescribed at present. The results of the present study have been very encouraging. The drug has been observed to be of significant benefit not only in mastalgia but also in regression of fibroadenomas.

In our study, 97.6 to $100 \%$ of women in mastalgia group reported complete relief at 12 weeks of therapy while $28 \%$ of fibroadenoma group reported complete relief at 12 weeks of therapy, partial relief in $31 \%$ and equivocal response in $41 \%$.
During follow-up after the end of study period, 3\% patients returned with the complaint of pain with a VAS scoring of 2 to 5 (mild pain). These were again put on drug therapy at decreased frequency of drug administration (once a week for 3 months) with a good response.

None of the patients with fibroadenoma with regression during the study period returned with relapse during follow-up.

Side effects observed were rare, namely allergic rash development $(2 \%)$ and a delay in menstruation of 7 to 10 days (14\%) during therapy.

\section{LIMITATION OF STUDY}

The study presents data only up to 6 months. The longterm results of Centchroman on recurrence need to be studied in the future. Furthermore, there is a need for prospective large randomized studies to compare this low cost drug with the standard but costly drugs being prescribed at present.

\section{DISCUSSION}

\section{Mastalgia}

Most women experience mastalgia (breast pain) at some time in life. It may be described as sharp, stabbing or shooting pain, feeling of heaviness or fullness in the breast, aching, tenderness, burning or pinching. Pain may be felt in one or both breasts, or just in part of one breast. Pain may also be felt in the armpit or upper arm as a radiating sensation in the underarm region. Pain occurring in the muscles and other tissues under the breast (chest wall) can be mistaken for breast pain which in reality is musculoskeletal pain. Breast pain is usually associated with a benign breast condition; it is rarely a sign of breast cancer.

There are two types of breast pain as follows:

\section{Cyclical Breast Pain (Cyclic Mastitis) ${ }^{4,5}$}

- Experienced around the time of a woman's menstrual period, with the pain easing after the period ends

- Usually occurs in both breasts

- More common in younger women and often disappears after menopause

- Often associated with premenstrual syndrome(PMS).

\section{Noncyclical Breast Pain}

- More common in women between 30 and 50 years of age

- May occur in or around only one breast

- Generally, the pain is present all the time and is in only one specific location.

Mastalgia whether cyclic (associated with menstrual periods) or noncyclic may be severely incapacitating for 
women. Cyclical mastalgia is a common problem that if pronounced, lasting for more than 1 week per cycle, can be sufficiently severe to interfere with usual activities, and has been associated with elevated mammography usage in young women. ${ }^{6}$

Many women with mastalgia worry more about the consequences of cancer than about the pain itself.

When the lumps become significant enough to be called cysts, the condition is called fibrocystic breast disease. Besides discomfort, perhaps the worst problem of this condition is that it can mimic the appearance of breast cancer on mammograms, leading to false alarms.

To make matters worse, fibrocystic changes can also hide true cancers, ${ }^{4}$ and some evidence hints that women with fibrocystic breast disease may also have a greater tendency toward breast cancer.

\section{ETIOLOGY}

Physicians continue to study the role that hormones play in cyclical mastalgia. One study has suggested that some women with cyclical mastalgia have a decreased ratio of progesterone to estrogen in the second half of the menstrual cycle. Other studies have found that an abnormality in the hormone prolactin ${ }^{7,8}$ may affect breast pain. Hormones can also affect cyclical breast pain as a result of stress-breast pain can increase or change its pattern with the hormone changes that occur during times of stress.

Hormones may not provide the total answer to cyclical breast pain, ${ }^{9}$ since pain is often more severe in one breast than in the other (hormones would tend to affect both breasts equally). Many physicians believe that a combination of hormonal activity and something in the breast that responds to this activity may hold the answer. However, more research is necessary in order to draw this conclusion.

The cause of cyclic breast pain ${ }^{10,11}$ is unclear. One theory, popular in Europe, suggests that higher than normal levels of the hormone prolactin maybe involved. Another theory attributes the condition to an imbalance of essential fatty acids. ${ }^{12-14}$

Several agents have been tried for mastalgia. The treatment modalities can be broadly divided into the following:

- Supportive

- Hormonal

- Nonhormonal and

- Surgical

\section{MANAGEMENT (GRAPH 3)}

Treatment options for breast pain depend on its cause, vary significantly including the following:

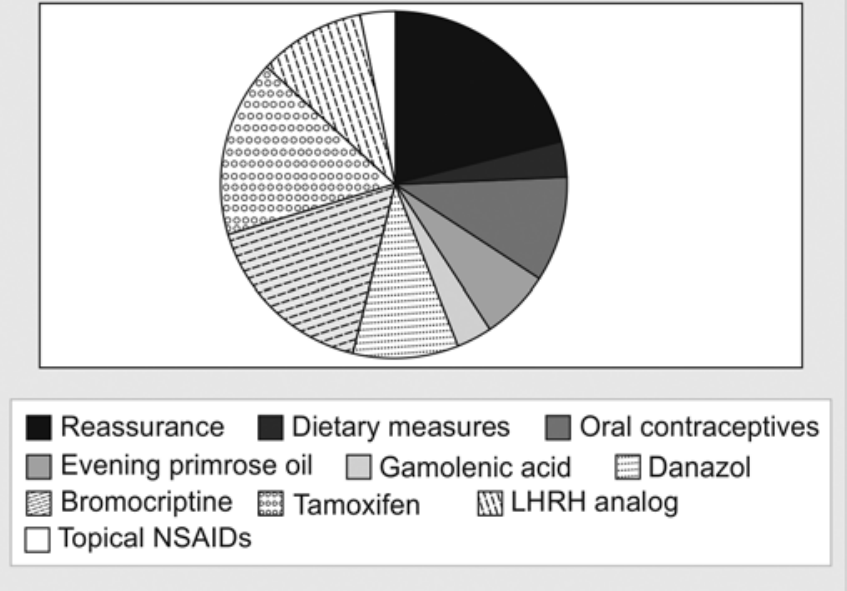

Graph 3: Current therapies in mastalgia management

- Reassurance: By far the most effective treatment as suggested by a Brazilian study quoting a success rate of up to $70 \%$ in a study comprising 85 patients. ${ }^{15}$

- Supportive therapy: Supportive therapy treats the symptoms of breast pain, but it does not treat the underlying cause of the breast pain. ${ }^{16}$ These may include: wearing a fitted, supportive bra, over-thecounter pain medicines (ibuprofen, acetaminophen, diclofenac cream), adding flaxseed to the diet, make changes to their diet (avoid caffeine and other stimulants (coffee, chocolate, tea, soft drinks) ${ }^{17,18}$ reduce salt and limit saturated fats).

- Oral contraceptive pills: Shown to have a protective effect in benign breast disorders. ${ }^{19}$ May reduce pain in some women.

- Diuretics: Diuretics were used earlier as water retention was thought to be the cause of mastalgia. Studies have found no correlation between retention of body water and symptoms. Now obsolete.

- Evening primrose oil: Evening primrose oil contains relatively high concentrations of the essential omega- 6 fatty acid named gamma-linolenic acid (GLA). On the theory that essential fatty acid imbalances play a role in cyclic mastalgia, evening primrose oil became a popular treatment for this condition. However, despite numerous positive anecdotes, there are considerable doubts regarding whether it is actually effective. ${ }^{20}$ The main supporting evidence for GLA comes from three small double-blind studies. Unfortunately, all of these suffered from significant limitations in study design and reporting. A very large (555 participants) and well-designed study failed to find GLA, with or without antioxidants, any more effective than placebo. ${ }^{21-24}$

- GLA: Gamolenic acid is an essential polyunsaturated fatty acid ${ }^{25-27}$ which is the main active component in evening primrose oil. In subjects with cyclical mastalgia 
low-plasma levels of GLA metabolites have been identified. In a study conducted at Cardiff University in 2005, comparing GLA, fatty acids and antioxidants with placebo fatty acids, the efficacy of GLA did not differ from placebo. ${ }^{28,29}$

- Danazol: Danazol is a derivative of the synthetic steroid ethisterone, a modified progestogen, also known as 17-alpha-ethinyl testosterone. It was approved by the US FDA as the first drug to specifically treat endometriosis in the early 1970s. Action of danazol in humans is not yet clearly defined as it only interferes with follicle stimulating hormone and leutinizing hormone at high doses. ${ }^{30,31}$ Androgenic side effects are hirsutizm, acne, deeping of voice, hot flashes, weight gain or adverse blood lipid profiles. Danazol appears to be the best agent for the treatment of severe mastalgia and nodularity with a success rate of up to $70 \% .^{32-34}$

- Bromocriptine: Bromocriptine is a dopamine agonist primarily used in pituitary tumors and parkinson's disease and hyperprolactinemia. It blocks the release of prolactin from the pituitary by dopaminergic receptor stimulation. It is effective in treatment of mastalgia but its use is limited by its side effects primarily nausea, orthostatic hypotension, vomiting and dizziness. ${ }^{35}$

- Tamoxifen: In a dose of $10 \mathrm{mg}$ per day, this estrogen receptor mixed agonist-antagonist has been found to be highly effective in treating cyclical as well as noncyclical mastalgia. The appropriate dose is $10 \mathrm{mg}$ daily for 3 months, repeated in case of relapseif necessary, according to current studies. Side effects are reported to be minimal. ${ }^{36,37}$

- Chasteberry: In Germany, the herb chasteberry is frequently used to treat cyclic mastalgia because of its effect on the pituitary gland to suppress the release of prolactin. Recently, evidence supports its effectiveness. A double-blind, placebo-controlled study, enrolling 178 women, evaluated chasteberry for PMS in general. The results over three menstrual cycles indicated that chasteberry reduced breast tenderness and other PMS symptoms. Benefits were also seen in two other double-blind trials enrolling a total of more than 250 women. ${ }^{38}$

- Ginkgo: Although the herb Ginkgo is primarily used to enhance memory and mental function, it may be helpful for breast tenderness as well. A double-blind, placebo-controlled study evaluated 143 women with PMS symptoms, 18 to 45 years of age, and followed them for two menstrual cycles. Each woman received either the Ginkgo extract ( $80 \mathrm{mg}$ twice daily) or placebo on day 16 of the first cycle. Treatment was continued until day 5 of the next cycle and resumed again on day 16 of that cycle. As compared to placebo, Ginkgo significantly relieved major symptoms of PMS, especially breast pain. ${ }^{39}$

- LHRH analog: Namely, Goserelin has been the subject of a large randomized multicenter study in the management of mastalgia. It has been found to be an effective short-term treatment, but owing to side effects its use is reserved for patients with pain refractory to other treatment modalities. ${ }^{40}$

- Surgical options: Fine needle aspiration-to relieve pain from a breast cyst. Surgery is sometimes done to remove a lump; mammoplasty is cases of large pendulous breasts. Surgical options are used when medical measures fail to give relief.

\section{Fibroadenoma}

Fibroadenomas are solid, benign tumors of the breast tissues. They are common in young women between the ages of 20 and 30.

There are two types of fibroadenomas:

- Simple fibroadenoma-most common type of fibroadenoma.

- Complex fibroadenoma-contain a mixture of cysts (fluid-filled sacs), enlarged breast lobules and calcifications.

Simple fibroadenomas do not increase a woman's risk of developing breast cancer. Even complex fibroadenomas do not become malignant (cancerous), but they may slightly increase a woman's risk of developing breast cancer in the future. ${ }^{41}$

\section{RISK FACTORS}

There are no known risk factors for fibroadenomas. It is thought that they are caused by the hormones that control a woman's menstrual cycle as fibroadenomas are more common in women of reproductive age and often disappear after menopause. Women may have one or several fibroadenomas, and they can occur in one or both breasts.

The signs and symptoms of fibroadenomas may include a lump that feels:

- Round

- Rubbery and smooth

- Well-defined with clear borders or edges

- Easy to move

- Painless

Most fibroadenomas are 1 and $2 \mathrm{~cm}$ in size, but can grow as large as $5 \mathrm{~cm}$ (giant fibroadenoma). ${ }^{42,43}$

Girls prefer to get it excised before the marriage. Till now, the only effective treatment available is excision, which leaves a scar on the breast and may damage mammary duct if present near the nipple-areolar complex. 
Viviani et al evaluated the effect of tamoxifen, an antiestrogenic drug on fibroadenoma showing regression insize by about $20 \%$ in the treatment arm. $^{44}$

Khanna et al evaluated estrogen receptor positivity and effect of danazol on fibroadenoma. They found that $62 \%$ of fibroadenoma responded to danazol, and response to danazol was significantly greater in ER-positive fibroadenoma.

Many studies have suggested 35 as a safe limit of age up to which fibroadenoma can be observed with no malignant change occurring in any of them.

There is wide discrepancy in the natural history of fibroadenoma regarding the change in size over time. Many fibroadenoma, if left alone, will remain static or gradually increase in size until 1 to $3 \mathrm{~cm}$ in diameter in 1 to 5 years. Thereafter, it is likely to remain static for the rest of patients' life or gradually decrease in size. A study shows 63 women with fibroadenoma for 2 years. They found that $31 \%$ of 201 lumps disappeared, $12 \%$ became smaller, $25 \%$ remained static, and $32 \%$ grew in size.

Dobie et al studied 201 patient of fibroadenoma of age less than 40 years, with conservative management for 5 years. During follow-up, 13\% were resolved, and $85 \%$ remained unchanged, while $2 \%$ increased in size. It appears that though fibroadenomas have a tendency to resolve naturally, the proportion of spontaneous regression is quite different in different studies. ${ }^{30}$

\section{MANAGEMENT}

The preferred management of multiple fibroadenomas is complete excision. However, this approach can lead to undesirable scarring or to extensive ductal damage if all the fibroadenomas are excised through one incision. Giant fibroadenomas tend to shrink after cessation of lactation, so their removal should be delayed until the patient's hormonal status returns to normal, and a smaller excision can be performed. It may be very disfiguring to excise juvenile fibroadenomas because of their large sizes; nevertheless, no recurrences were reported after complete excision, and normal and symmetrical development of the breasts can be anticipated.

Because of the increased incidence of carcinoma in older women, two different treatment approaches are recommended for fibroadenomas in women younger and older than 35 .

For women in which a fibroadenoma is diagnosed before the age of 35 , recommend treatment is conservative management with a protocol of follow-up every 6 months in order to detect any changes of the lesion. In cases of regression, the follow-up should continue until complete regression. Fibroadenomas that either do not completely regress, or remain unchanged by the age of 35 , should be excised surgically. Fibroadenomas that become larger should be excised without delay. In patients with a family history of breast cancer, or known changes of complex fibroadenoma, we recommend excisional biopsy shortly after diagnosis has been established.

\section{REFERENCES}

1. Nityanand S, Chandrawati $X$, Singh L, Srivastava JS, Kamboj YR. Clinical evaluation of Centchroman: a new oral contraceptive. In: Puri CP, VanLook PFa, editors. Hormone antagonists for fertility regulation. Ind Soc Study Reprod Fert, India, Bombay, 1998. p. 223-230.

2. Tejwani PL, et al. Centchroman regresses mastalgia: A randomised comparison with Danazol. Ind J Surg 2011 MayJun;73930:199-205.

3. Dhar A, Srivastava. Role of centchroman in regression of mastalgia and fibroadenoma. World J Surg 2007;31:1178-1184.

4. Sharma AK, Mishra SK, Salia M, et al. Cyclical mastalgia-is it a manifestation of aberration in lipid metabolism? Ind J Physiol Pharmacol 1994;38:267-271.

5. Wuttke W, Splitt G, Gorkow C, et al. Treatment of cyclical mastalgia: results of a randomized, placebo-controlled, double-blind study [translated from German]. Geburtsh Frauenheilk 1997;57:569-574.

6. Kubista E, Muller G, Spona J. Treatment of mastopathy associated with cyclic mastodynia: clinical results and hormone profiles [translated from German]. Gynakol Rundsch 1986;26:65-79.

7. Kumar S, Mansel RE, Hughes LE, et al. Prolactin response to thyrotropin-releasing hormone stimulation and dopaminergic inhibition in benign breast disease. Cancer 1984;53:1311-1315.

8. Khanna AK, Tapodar JK, Khanna HD, et al. Behaviour of estrogen receptor, histological correlation, and clinical outcome in patients with benign breast disorders. Eur J Surg 2002;168:631-634.

9. Swain MC, Hayward JL, Bulbrool RD. Plasma oestradiol and progesterone in benign breast disease. Eur J Cancer 1973;9:553-556.

10. Hughes LE, Mansel RE, Webster DJT. Breast pain nodularity. In: Hughes LE, Mansell RE, Webster DJT. Benign Disorders and diseases of the breast: concepts and clinical management. 2nd ed. London: WB Saunders Company; 2000. p. 95-121.

11. Lawrence WB, Valerie PJ. Diagnosis of diseases of the breast. 1st ed. Philadelphia: WB Saunders Company; 1997. p. 385.

12. Malarkey WB, Schroeder LL, Stevens VC, et al. Twenty-fourhour preoperative endocrine profiles in women with benign and malignant breast disease. Cancer Res 1977;37:4655-4659.

13. Cole EN, Sellwood RA, England PC, et al. Serum prolactin concentration on benign breast disease throughout the menstrual cycle. Eur J Cancer 1977;13:597-603.

14. Peters F, Pickardt CR, Zimmerman G, et al. PRL, TSH and thyroid hormones in benign breast disease. Klin Wochenschr 1981;59:403-407.

15. Barros AC, Mottola J, Ruiz, et al. Reassurance in the treatment of mastalgia. Breast J 1999;5:162-165.

16. Hadi MS. Sports brassiere: is it a solution for mastalgia? Breast J 2000;6:407-409.

17. Ernster VL Mason L, Goodson WH, et al. Effects of caffeine free diet on benign breast disease: a randomized trial. Surgery 1982;91:263-267. 
18. Minton JP, Foeking MK, Webster DJT, et al. Response of fibrocystic disease to caffeine withdrawal and correlation with cyclic nucleotides with breast disease. Am J Obstet Gynecol 1979;135:157.

19. Ory H, Cole P, MacMahon B. Oral contraceptives and reduced risk of benign breast diseases. N Engl J Med 1976;294:419-422.

20. Rohan TE, Cook MG, Potter JD. A case control study of diet and benign proliferative epithelial disorder of the breast. Cancer Res 1990;50:3176-3181.

21. Pashby NL, Mansel RE, Hughes, et al. A clinical trial of evening primrose oil in mastalgia. Br J Surg 1981;68:801.

22. Blommers J, de Lange-De Kleek ES, Kuik DJ, et al. Evening primrose oil and fish oil for severe chronic mastalgia: a randomized, double blind, controlled trial. Am J Obstet Gynecol 2002;187:1389-1394.

23. Kollias J, Macmillan RD, Sibbering DM, et al. Effect of evening primrose oil on clinically diagnosed fibroadenomas. Breast 2000;9:35-36.

24. Pruthi S, Wahner-Roedler DL, Torkelson CJ, et al. Vitamin E and evening primrose oil for management of cyclical mastalgia: a randomized pilot study. Altern Med Rev 2010;15(1): 59-67.

25. Ingram DM, Hickling $C$, West $\mathrm{L}$, et al. A double-blind randomized controlled trial of isoflavones in the treatment of cyclical mastalgia. The Breast 2002;11:170-174.

26. Horrobin DF, Manku MS, Brush M, et al. Abnormalities in plasma essential fatty acid levels in women with premenstrual syndrome and with nonmalignant breast disease. J Nutr Med 1991;2:259-264.

27. Mansel RE, Gateley CA, Harrison BJ, et al. Effects and tolerability of n-6 essential fatty acid supplementation in patients with recurrent breast cysts-a randomized doubleblind placebo-controlled trial. J Nutr Med 1990;1:195-200.

28. Khanna AK, Tapodar JK, Khanna HD. Behaviour of estrogen receptor, histological correlation and clinical outcome in patients with benign breast disorder. Eur J Surg 2002;168:631.

29. Goyal A, Mansel RE. On behalf of the Efamast study group: a randomized multicenter study of gamolenic acid (Efamast) with and without antioxidant vitamins and minerals in the management of mastalgia. Breast J 2005;11:41-47.

30. Hughes LE, Mansel RE, Webster DJT. Aberration of normal development and involution: a new perspective on pathogenesis and nomenclature of benign breast disorders. Lancet 1987;11:1316-1319.
31. Greenblatt RB, Dmowske WP, Mhesh VB, et al. Clinical studies with an antigonadotrophin-Danazol. Fertil Steril 1971;22:102-112.

32. Asch RH, Greenblatt RB. The use of an impeded androgen Danazol in the management of benign breast disorders. Am J Obstet Gynecol 1971;127:130-134.

33. Harrison BJ, Maddox PR, Hughes LE. Maintenance therapy of cyclical mastalgia using low dose Danazol. J R Coll Surg Edinb 1989;34:79-84.

34. Hinton CP, Bishop HM, Holliday HW, et al. A doubleblind controlled trial of danazol and bromocriptine in the management of severe cyclical breast pain. Br J Clin Pract 1986;40:326-330.

35. ManselRE. Areview of theroleofbromocriptineinsymptomatic benign breast disease. Res Clin Forum 1981;3:61-63.

36. V ivani RS, Gebrim LH, Baracat EC, De Lima GR. Evaluation of the ultrasonographic volume of breast fibroadenomas in women treated with tamoxifen. Minerva Gynecol 2002;54 (6):531-535.

37. Fentiman IS, Caleffi M, Hamed $\mathrm{H}$, et al. Dosage and duration of tamoxifen for mastalgia: a controlled trial. Br J Surg 1988;75:845-846.

38. Kamboj VP, Kar AB. Effect of some non-steroidal antifertility agents on the biochemistry of the uterus and uterine fluids in rats.indian J Exp Biol 1973;11:479-483.

39. Fentiman IS, Caleffi M, Brame K, et al. Double-blind controlled trial of tamoxifen therapy for mastalgia. Lancet 1986;8376:287-288.

40. Mansal E, Goyal A, Preece P, et al. European randomized, multicenter study of goserelin (Zoladex) in the management of mastalgia. Am J Obstet Gynecol 2004;191:1942-1949.

41. Yu H, Rohan TE, Cook MG, Howe GR. Risk factor for fibroadenoma: a case control study in Australia. Am J Epidemiol 1992;135:247-258.

42. Ravnihar B, Segel DG, Lindther J. An epidemiologic study of breast cancer and benign breast neoplasm in relation to the oral contraceptive and estrogen use. Eur J Cancer 1979;15:395-405.

43. Canny PF, Berkowitz GS, Kelsey JL. Fibroadenoma and the use of exogenous hormones: a case control study. Am J Epidemiol 1988;127:454-461.

44. Vivani RS, Gebrim LH, Baracat EC, De Lima GR. Evaluation of the ultrasonographic volume of breast fibroadenomas in women treated with tamoxifen. Minerva Gynecol 2002;54: 531-535. 